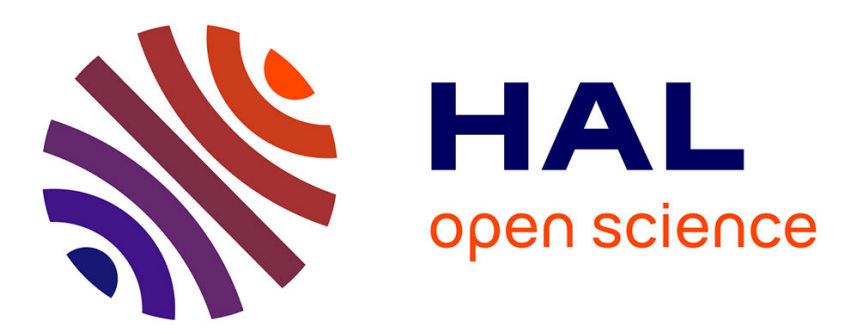

\title{
Plane Behaviour at High Strain Rates of a Quasi-Unidirectional E-Glass/Polyester Composite: Impact Application
}

\author{
Claire Kammerer, A. Neme
}

\section{- To cite this version:}

Claire Kammerer, A. Neme. Plane Behaviour at High Strain Rates of a Quasi-Unidirectional EGlass/Polyester Composite: Impact Application. Journal de Physique IV Proceedings, 1997, 07 (C3), pp.C3-693-C3-698. 10.1051/jp4:19973118 . jpa-00255403

\section{HAL Id: jpa-00255403 https://hal.science/jpa-00255403}

Submitted on 1 Jan 1997

HAL is a multi-disciplinary open access archive for the deposit and dissemination of scientific research documents, whether they are published or not. The documents may come from teaching and research institutions in France or abroad, or from public or private research centers.
L'archive ouverte pluridisciplinaire HAL, est destinée au dépôt et à la diffusion de documents scientifiques de niveau recherche, publiés ou non, émanant des établissements d'enseignement et de recherche français ou étrangers, des laboratoires publics ou privés. 


\title{
Plane Behaviour at High Strain Rates of a Quasi-Unidirectional E-Glass/Polyester Composite: Impact Application
}

\author{
C. Kammerer and A. Neme* \\ ETCA/CREA/MCS, 16 bis av. Prieur de la Côte d'Or, 94114 Arcueil, France \\ * ENSIETA, DER Mécanique, 2 rue François Verny, 29240 Brest, France
}

\begin{abstract}
Dealing with the plane behaviour of a composite quasi-unidirectional elementary ply made of $\mathrm{E}$ glass/polyester, this paper contributes to the study of impact phenomena on ceramic/composite bi-layered targets. Firstly, a quasistatic modelisation of the elementary ply behavior, in plane tensile and plane shear, is presented. It allows a good description of the residual strains and of stiffness losses. The second part presents a new fixing method for testing orthotropic materials with the tensile Hopkinson bars apparatus. Then, the elementary ply is tested at high strain rates and these tests are simulated with the constitutive model. Impact simulations incorporating a proposed failure criterion which is proposed are performed, and then compared with experimental.
\end{abstract}

\begin{abstract}
Résumé. Ce travail s'intéresse au comportement plan du pli élémentaire quasi-unidirectionnel d'un composite en verre E/polyester et contribue à l'étude de l'impact sur des cibles bicouches. Tout d'abord, une modélisation quasi-statique du comportement plan du pli est rappelée. Celle-ci permet une bonne description des déformations résiduelles et des pertes de raideurs. La seconde partie du travail présente une nouvelle méthode de fixation pour tester les matériaux orthotropes aux barres d'Hopkinson. Le pli élémentaire est soumis à de grandes vitesses de déformation et ces essais sont simulés en utilisant la loi de comportement identifiée. Des simulations d'impact, comprenant un critère de rupture qui est proposé et testé, sont alors comparées avec l'expérience.
\end{abstract}

\section{INTRODUCTION}

The aim of this research, conducted at Centre de Recherches et d'Etudes d'Arcueil (DGADCE/ETC4), is the study of the impact of small and medium caliber projectiles on front-faced ceramic back-faced composite targets ("bi-layered targets"). The kinds of damage in the composite plate of a bi-layered target being the same as those observed in a composite plate impacted without a front-faced ceramic tile [1], the plane constitutive law of the elementary ply is studied here.

Impacted composite plates usually exhibit two kinds of damage : transverse cracking and delamination [2]. It is possible to consider the composite plate as a stacking of plies and interfaces [3] : the elementary plies are responsible for the plane constitutive law of the composite plate, and consequently for the transverse cracking ; the interfaces between the elementary plies are responsible for the out of plane constitutive law of the plate, their rupture is delamination.

Several studies deal with the constitutive law of elementary plies, using different approaches [4] [5]. But, for our impact applications here, we are interested in the constitutive law under high strain rates. The studied composite is made of quasi-unidirectional E-glass/polyester elementary plies (rate of woof : $5 \%$; specific rate of fibers : $80 \%$ ).

The first part presents, with quasistatic tensile tests, an identification of the plane tensile and shear behaviour of the elementary ply. A constitutive law has been written [1] to describe it.

In order to perform tensile tests with high strain rates, the third part suggests a new fixing method and a new geometry for specimens to test orthotropic materials with the Hopkinson bars apparatus. The simulations of these tests are carried out with the constitutive law identified under quasistatic solicitations.

In a fourth and last part, a simple rupture criterion is suggested. The numerical impact simulations of a spherical projectile against unidirectional stacking composite plates are compared with experiments.

\section{PLANE QUASI-STATIC CONSTITUTIVE MODEL FOR THE ELEMENTARY PLY}

In this part, we present some results of [1] about the quasi-static characterization of the plane behavior of the elementary ply and its modelisation by writing a constitutive law. The specific stress concept is used [6].

Several tests on different stackings have been conducted : $\left[0^{\circ}\right]_{n},\left[90^{\circ}\right]_{n},\left[0^{\circ}, 90^{\circ}\right]_{n}$ et $\left[45^{\circ},-45^{\circ}\right]_{n}$. The tensile tests on $\left[0^{\circ}\right]_{n}$ specimens had shown a linear elastic behaviour, a brittle rupture and no sensitivity to 
strain rate in the direction of fibers. The behaviour in transverse direction is given by the tensile tests on $\left[90^{\circ}\right]_{8}$ specimens. It is not linear, it is strongly strain rate sensitive and exhibits residual strains and losses in specific stiffnesses (Fig. 1). There are also some recovery phenomena (between unloading and reloading, the plastic strains decrease) and hysteresis cycles. These characteristics can be observed in tensile tests on $\left[0^{\circ}, 90^{\circ}\right]_{\mathrm{nS}}$ specimens too [1].

The losses in stiffness, in both directions, are non-reversible phenomena. The (positive) plastic strains may be explained by the fact that some transverse cracks do not close completely after their opening during the last loading-unloading.

The shear constitutive law of the ply has the same characteristics : sensitivities to strain rates, plastic strains and losses in constitutive properties (Fig. 1).

We have chosen the elastoviscoplasticity concept to represent the plastic strains and the strain rate sensitivities. In order to accurately describe the phenomena of recovery and hysteresis cycles, a kinematic hardening is retained. If the evolution of stiffnesses is drawn versus the maximum of specific stress [1], a strain rate sensitivity appears for damage. Therefore, a new constitutive model is suggested to represent these sensitivities. This model is founded on the "bi-material" concept and differs from the damage law depending explicitly on damage rate [3].

The "bi-material" concept has been developped by Moumni and N'Guyen [8]. This concept considers that the ply is made of two elementary and fictitious materials. The first one has the behaviour of the virgin ply, the second one has the behaviour of the damaged material just before its final breaking. The transformation of the first in the second is non-reversible. The proportions of these two materials are characterized by an internal vector variable. Here, an elastoviscoplastic, with kinematic hardening, behaviour [9] is chosen for the two materials.

With an explicite integration and an algorithm of minimization, the constitutive law parameters of the elementary ply are identified [1]. The optimized parameters allow to simulate plane tensile behaviour and plane shear behaviour of the ply. Figure 1 presents some results.

There is a good agreement between experiments and simulations. The strain rate sensitivities and the losses in stiffnesses are well represented in the specific stress-strains curves. As regards the plastic strains and recovery phenomena, in tensile tests on both $\left[90^{\circ}\right]_{\mathrm{n}}$ and $\left[45^{\circ},-45^{\circ}\right]_{\mathrm{nS}}$ specimens, numerical and experimental results are of the same order of magnitude.
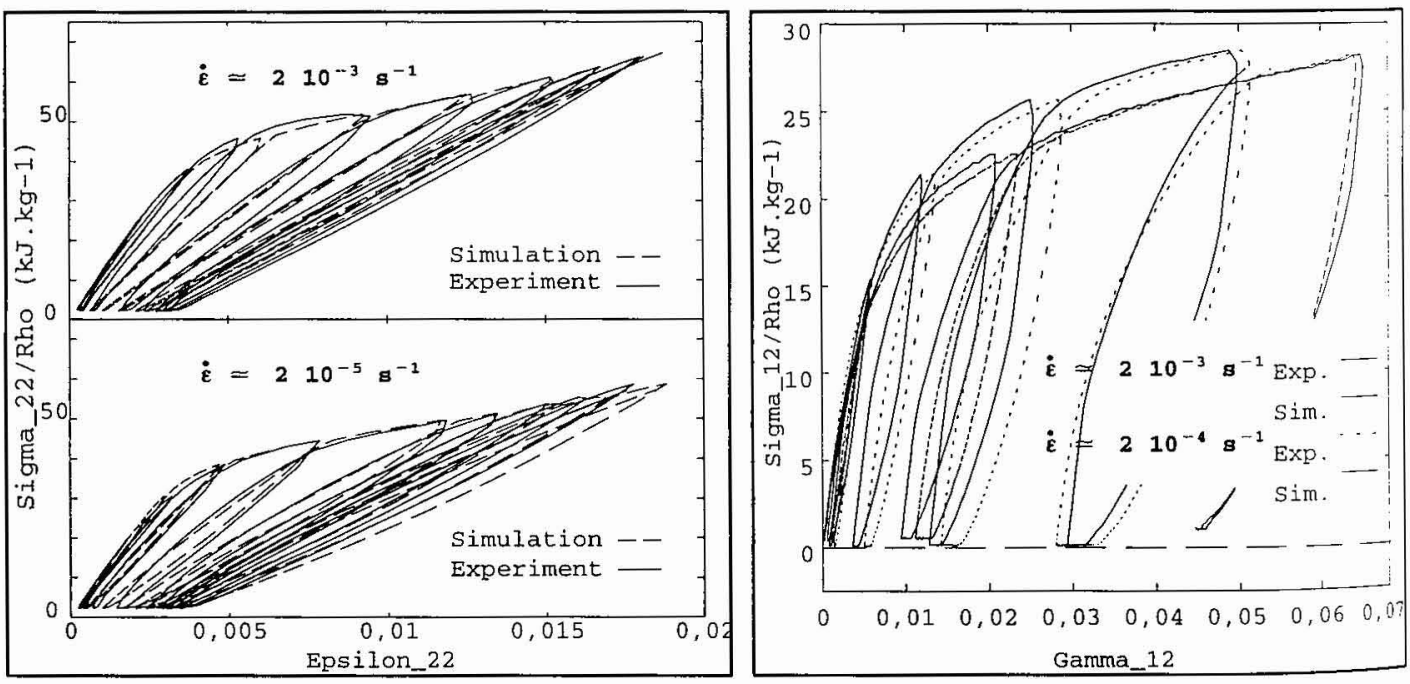

Figure 1: Quasistatic tensile tests on $\left[90^{\circ}\right]_{\Pi}$ (left) and $\left[45^{\circ},-45^{\circ}\right]_{n S}$ (right) specimens : experiments and simulations.

\section{TENSILE HOPKINSON BARS APPARATUS : TESTS AND SIMULATIONS}

The Hopkinson bars apparatus allows the study of behaviour of materials at high strain rates. This apparatus is particularly used in dynamic compression : it is easy to put a cylindrical specimen between the two parallel 
plane surfaces of the incident and transmitted bars [10]. Unfortunately, in dynamic tensile solicitations, the specimen must be held on the bars. In the case of isotropic materials, the most common configuration is a simple screwing [11]. In the case of orthotropic materials, this configuration cannot be used, and consequently the main difficulties lie in the fixing method of the specimen.

\subsection{New design for the fixing method of orthotropic specimens}

In order to carry out tensile tests at high strain rates with the Hopkinson bars apparatus, a new fixing method suitable for orthotropic materials has been designed. It (Fig. 2) has several advantages : it requires neither a third material, the behaviour of which might not be fully documented, nor any intermediate part between bars and sample, and thus the numerical simulation is quite easy. The specimen has a hourglass shape and it is put between the ends of incident and transmitted bars. The plane contact surfaces, between the specimen and the bars, must be, as far as possible, the largest and the most perpendicular to the axis of both bars.

This geometry of fixing has the advantage of being mere (with the minimum of parts, and consequently with the minimum of contacts) and therefore, it enables numerical simulations, with the finite elements method, of the set \{incident bar, specimen, transmitted bar\}.

The incident bar has an anvil at its opposite end. The incident tensile wave is created by launching a cylindrical hollow projectile against this anvil.

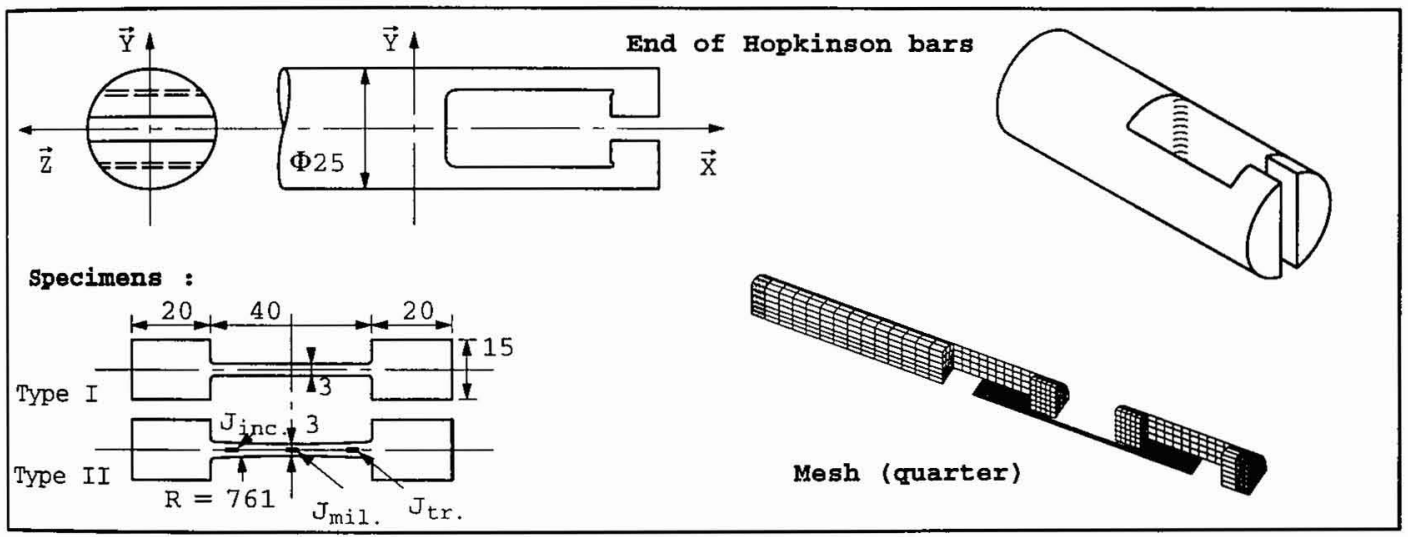

Figure 2: New fixing and specimen geometries to test orthotropic materials at high strain rates.

\subsection{Dynamic tensile tests on E-glass/polyester : experiments and simulations}

In this configuration, and because the measured strains are low (compared with those measured in metals), every slack between the ends of bars and the specimen, and every defect of alignment between the plane of specimen and the axis of the bars lead to errors because the simulation is carried out with the assumption of perfect contacts. A pre-tension system and wedges have been used to improve the measures. Dynamic tensile tests on $\left[0^{\circ}\right]_{\mathrm{n}},\left[90^{\circ}\right]_{\mathrm{n}},\left[0^{\circ}, 90^{\circ}\right]_{\mathrm{nS}}$ and $\left[45^{\circ},-45^{\circ}\right]_{\mathrm{nS}}$ specimens have been conducted in this way.

Several geometries of the center of specimens (Fig. 2) have been tested to localize the rupture in the center of $\left[90^{\circ}\right]_{\mathrm{n}}$ specimens : for example a constant section (Type I) or a reduced section (Type II). The second geometry ensures that the rupture is localized in the center of the sample, where the gauge has been stuck, whereas in the first case, the rupture occurs nears the transmitted shoulder (Fig. 3).

Six strain gauges have been stuck on the apparatus to simulate these tests, and then to compare the experiments with the simulations : the first on the incident bar, four on the specimen $\left(\mathrm{J}_{\text {mil. }}\right.$ and $\mathrm{J}^{\mathrm{R}}{ }_{\text {mil. }}$ are placed in the center of the specimen, one on each face, $\mathrm{J}_{\text {inc. }}$ and $\mathrm{J}_{\text {ir. }}$ symmetrically to $\mathrm{J}_{\text {mil. }}$, as presented on figure 2 ), the last one is placed on the transmitted bar.

For the numerical simulations, the finite element code Abaqus 5.4 code [12], with implicit integration has been used. The mesh, on figure 2, represents the set \{incident bar, specimen, transmitted bar\}. We use semi-infinite elements which can absorb every reflexion wave and avoid the meshing of the whole bars. The specimen is meshed with plane stress elements. 

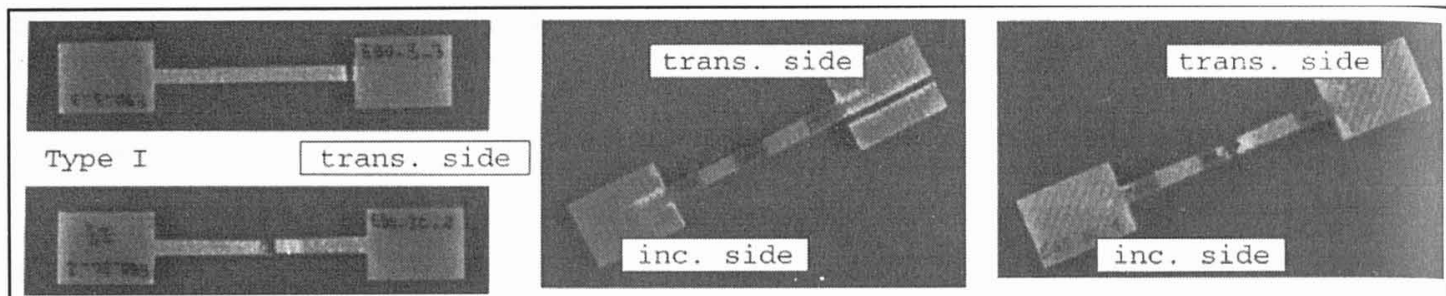

Type II $\quad\left[90^{\circ}\right]_{\mathrm{n}}$

Type II $\left[0^{\circ}\right]_{\mathbf{n}}$

Type II $\left[45^{\circ},-45^{\circ}\right] \mathrm{nS}$

Figure 3: Rupture of dynamic tensile specimens.

The constitutive law identified with quasistatic loadings has been written in a "UMAT" subroutine. If means that the user, with the Abaqus code, can define his own material. In this subroutine, the user must compute the stresses, the internal variables and the Jacobian matrix at the end of each time increment.

The measure of the load is provided by the incident strains recorded by the incident gauge; the experiment/simulation comparison is achieved by looking at the differences between experimental strains measured on the specimen gauges and computed strains obtained on the meshed specimen, as presented in Fig. 4 (the specimens have not broken during these recordings).

In this way, the constitutive law is extrapolated from quasistatic solicitations, where it has been identified, to the area of high strain rates (from 100 to $200 \mathrm{~s}^{-1}$ ). A few remarks can be made :

- In direction $\overrightarrow{2}$, there is a good agreement between experiment and simulation. Moreover, several computations show that, at high strain rates, the viscoplastic characteristic of the elementary ply vanishes out. and only the stiffness losses are important [1].

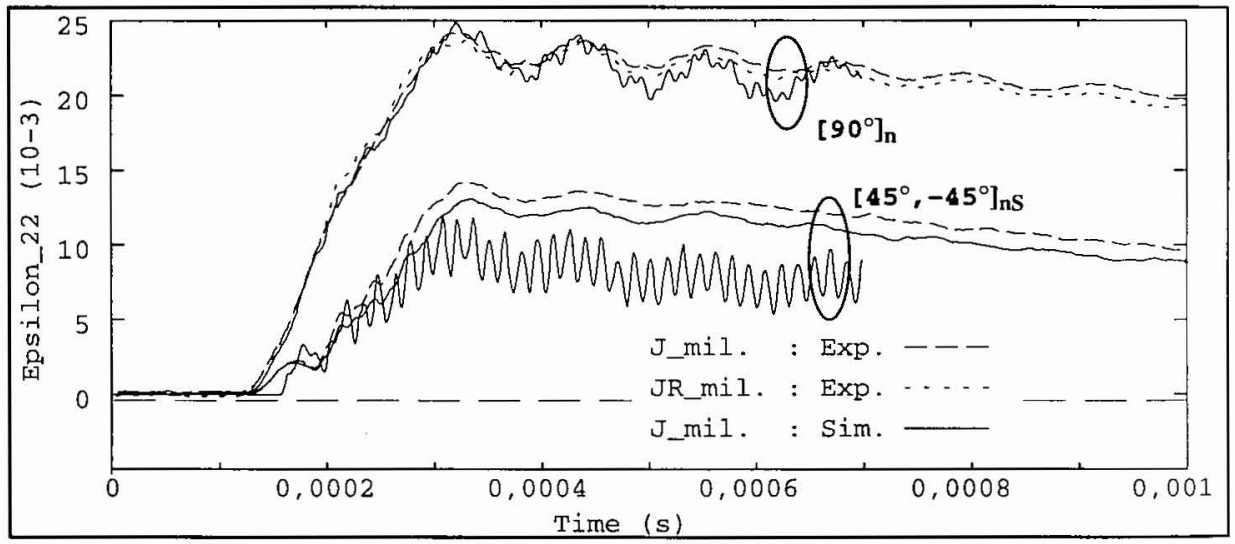

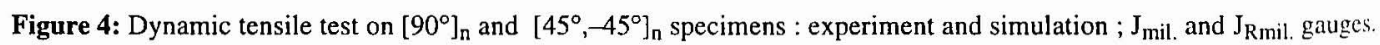

- In direction $\vec{i}$, the behaviour is essentially elastic. At high strain rates, it has not been possible to test it as far as the rupture does not occur in the center of specimens (Fig. 3) : the shoulders break by shearing. In fact, in this configuration, we study the plane shear behaviour of the specimen in the shoulders.

- The dynamic tensile tests on $\left[45^{\circ},-45^{\circ}\right]_{n s}$ specimens have allowed to test the elementary ply in plane shear and bi-tension. Although we have simulated the slack between the specimen and the ends of bars, there is still a difference between the simulation and the experiment (Fig. 4). In our opinion, the quasistatic tests should be performed on a larger range of strain and strain rates, so that the constitutive law can be identified more accurately.

\section{IMPACT TESTS AND SIMULATIONS}

\subsection{Rupture criterion}

In each direction, the plane tensile breaking is brittle. Because of the quasi-unidirectionality of the elementary ply (rate of woof : $5 \%$ ), it is possible to assume that the ultimate tensile load is given by the fibers 
breaking. This assumption is reinforced by some values of maximum strains : at low strain rates, they are equivalent [1]. But there is a sensitivity to strain rate as it is shown on the figure $5:$ the maximum strains versus the logarithm of strain rate. A linear statement linking the maximum strain with the logarithm of strain rate can be written (dashed line on figure 5). Then, a tensile rupture criterion follows as :

"If $\dot{\varepsilon}_{\mathrm{ii}} \geq 0$ and if $\varepsilon_{\mathrm{ii}} \geq \max \left[\varepsilon_{0}, \varepsilon_{1}+\chi \ln \left(\dot{\varepsilon}_{\mathrm{ii}}\right)\right]$, a tensile rupture occurs in direction $\overrightarrow{\mathrm{i}}$ "

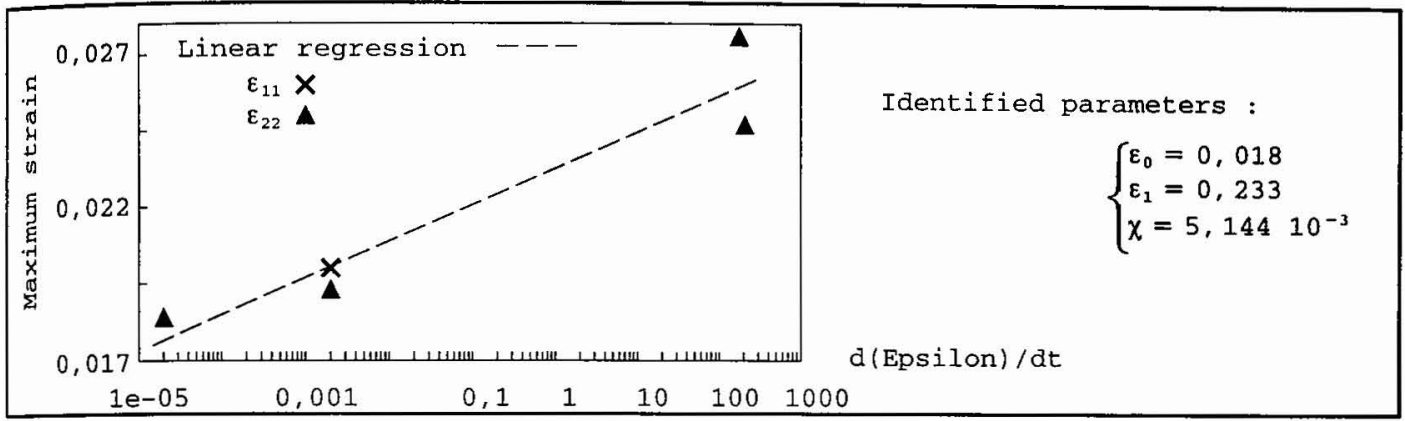

Figure 5: Maximal tensile strains versus strain rates.

\subsection{Impact tests and simulations}

A gas gun has been used to launch steel spherical $11 \mathrm{~mm}$ diameter projectiles against unidirectional stacking E-glass/polyester composite plates $(200 \times 200 \times 3 \mathrm{~mm})$. This stacking has been chosen to have the least important delamination [13] [14]. The incident and residual velocities of the projectile are measured, they are shown on figure 6 . The ballistic limit of this plate is about $180 \mathrm{~m} \cdot \mathrm{s}^{-1}$.

The finite element code Abaqus, with an explicit integration, has been used to simulate these tests. A subroutine "vumat" has been written in order to describe the constitutive law of the elementary ply and its tensile rupture. The projectile is mesed as a rigid body and the plate is meshed of shell elements with five integration points in their thickness. When the rupture criterion is reached, the Abaqus code prescribes out the values of stresses equal to zero.

Then, some elements can be "destroyed" under the projectile. The velocity of projectile is recorded during its interaction with the composite plate. The residual velocity, after the interaction, is given by the stabilized velocity. The comparison between experiments and simulations is done considering the difference between experimental and simulated residual velocities.

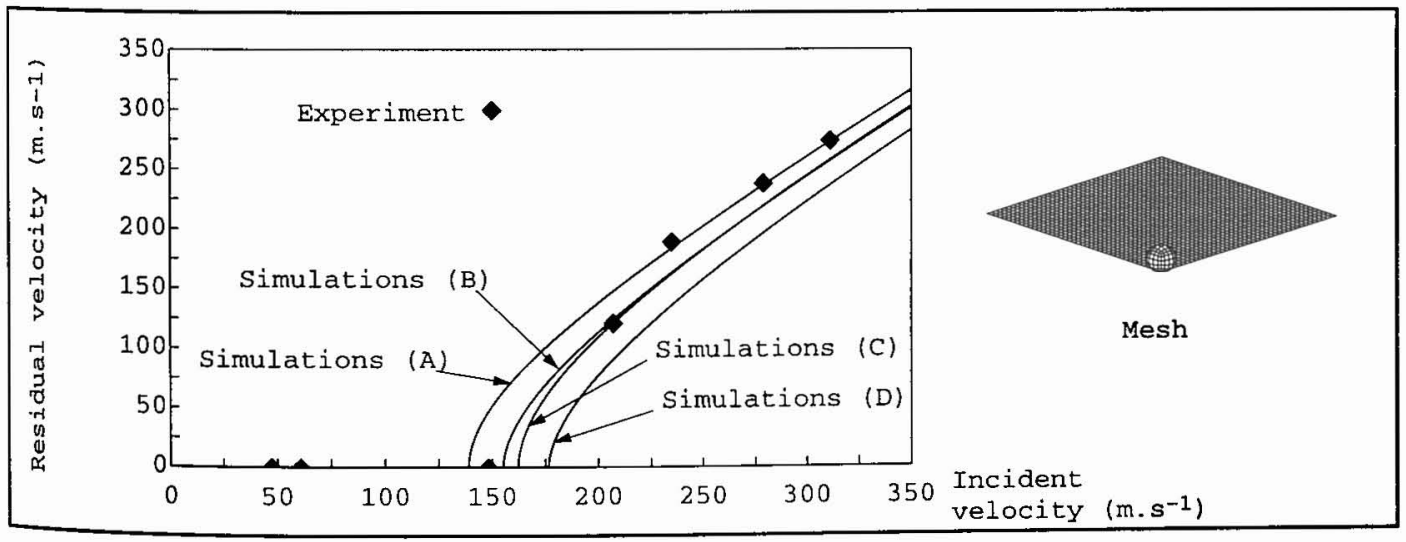

Figure 6: Impact tests and simulations : incident and residual velocities.

Figure 6 shows four simulations (with the same tensile rupture criterion) : (A), an elastoviscoplastic "bi-material" constitutive model ; (B), an elastoviscoplastic "bi-material" tension and elastic shearing ; (C), an elastic "bi-material" tension and elastic shearing ; (D), an elastic constitutive model. 
Several remarks can be made about these results. At high incident velocities, the constitutive model discussed in the first part of the paper and the tensile rupture criterion provide a good prediction of the experimental residual velocities. But, for incident velocities near the ballistic limit, there are still some differences. Perhaps, according to the conclusions of Beaumont [13], these are due to the coming out of important delamination in the composite plate, even if unidirectional stackings reduce it. When the incident velocity increases, delamination decreases and the modelisation becomes more accurate.

There is also a great difference between the ballistic limits obtained by simulations (A) and (B) : it shows that the modelisation of shear behaviour is important. Lastly, the simulations (D) justify the choice of a quite elaborate modelisation of the elementary ply.

\section{CONCLUSION - PROSPECTS}

A plane constitutive law for quasi-unidirectional composite has been written to take into account the sensitivities to strain rate of both the stiffnesses losses and the plastic strains. This constitutive law, based on the "bi-material" concept, has been identified at low strain rates (quasistatic loadings) and has been tested at high strain rates. To carry out these latter, using the tensile Hopkinson bar apparatus, a new method to fix the specimen at the ends of the bars has been proposed. Then, after retaining a tensile rupture criterion based on maximum strains, impact tests has been performed on a unidirectional stacking composite plate. The simulation of these tests has provided good results.

It is now possible to identify the behaviour of another quasi-unidirectional organic matrix composite, different from E-glass/polyester, with the same elastoviscoplastic "bi-material" constitutive law.

The ongoing research bears on the study of the interface between two elementary plies, in a non-unidirectional stacking composite plate in order to describe the impact response of such structures thoroughly.

\section{Acknowledgements}

The work performed at the Centre de Recherches et d'Etudes d'Arcueil was supported by DRET/STRDT. The authors also wish to thank Thierry Bretheau for his scientific support and Raymond Le Prat for his invaluable assistance.

\section{References}

[1] Kammerer C., PhD thesis, Université de Paris XIII, Villetaneuse, 1996.

[2] Hitchen \& Kemp, Composites, 26, pp. 207-214, 1995.

[3] Allix O., Bras F. \& Déu J.F., J. Phys. IV 4 (1994), pp. C8 527-C8 532.

[4] Lesne, Lesne P.M. \& Maire J.F., “Application d'un modèle viscoplastique à l'étude d'un matériau composite à matrice organique". In Proc. 9ème Journées Nat. Comp., Saint-Etienne, 1994, pp. 485-494.

[5] Aussedat, Thionnet \& Renard, C.R.A.S. Paris, 320 (1995), Série IIb, pp. 123-130.

[6] Nême A. \& Dahan N., C.R.A.S. Paris, 318, Série II, pp. 435-442, 1994.

[7] Kammerer C. \& Nême A., "Thermodynamic constitutive model for the damageable elastoviscoplastic behaviour of E-glass/polyester unidirectional plies". In Proc. $5^{\text {th }}$ Int. Symp. on Plasticity, Osaka. Dym. plast. and struct. behaviours, pp. 969-972, 1995.

[8] Moumni Z. \& N'Guyen Q.S., "Etude d'un modèle de changement de phase : application à l'endommagement fragile, progressif et partiel". In Proc. Colloque Nat. Struct., Giens, 1993, 2, pp. $593-602$.

[9] Lemaître J. \& Chaboche J.L., "Mécanique des matériaux solides", Dunod, Paris, 1988.

[10] Lichtenberger, Rapport DYMAT, n RE/002/87, 1987.

[11] Harding, Wood \& Campbell, J. Mech. Engng. Sc. 2, pp. 88-, 1960.

[12] Hibitt, Karlsson \& Sorensen, Inc. "Abaqus Users's" version 5.4-1.

[13] Beaumont N., PhD thesis, Ecole Nationale Supérieure des Mines de Paris, Paris, 1990.

[14] Chaillou F., PhD thesis, Université de Bordeaux I, Bordeaux, 1992.

[15] Kammerer C. \& Nême A., Eur. J. of Mech., submitted, 1996. 